\title{
Hydrogen-bonding network in the crystal of bis[1-(diaminomethylene)thiouron-1-ium] oxalate
}

\author{
Genivaldo Julio Perpétuo a Jan Janczak ${ }^{\mathrm{b}, *}$ \\ ${ }^{a}$ Departamento de Física, Instituto de Ciências Exatas e Biológicas, Universidade Federal de Ouro Preto, 35400-000 Ouro Preto, MG, Brazil \\ ${ }^{\mathrm{b}}$ Institute of Low Temperature and Structure Research, Polish Academy of Sciences, PO Box 1410, 50950 Wrocław, Poland
}

\section{A R T I C L E I N F O}

\section{Article history:}

Received 19 July 2011

Received in revised form 12 October 2011

Accepted 12 October 2011

Available online 10 November 2011

\section{Keywords:}

Bis[1-(diaminomethylene)thiouron-1-ium]

oxalate

Crystal structure

Hydrogen bonds

Vibrational spectroscopy

\begin{abstract}
A B S T R A C T
The single crystals of bis[1-(diaminomethylene)thiouron-1-ium] oxalate were grown using a solution growth technique. The compound crystallises in the centrosymmetric $C 2 / c$ space group of the monoclinic system. The conformation of the 1-(diaminomethylene)thiouron-1-ium cation is not strictly planar, but twisted. Both arms of the cation are oppositely rotated by $5.0(1)^{\circ}$ around the $\mathrm{C}-\mathrm{N}$ bonds involving the central $\mathrm{N}$ atom. The centrosymmetric oxalate(2-) anion is planar. The arrangement of oppositely charged components, i.e. 1-(diaminomethylene)thiouron-1-ium cations and oxalate(2-) anions in the crystal is mainly determined by ionic and hydrogen bonding interactions forming three-dimensional network. The compound was also characterised by the FT-IR and Raman spectroscopy. The characteristic bands of the $\mathrm{NH}_{2}, \mathrm{C}=\mathrm{S}$ and $\mathrm{COO}^{-}$groups as well as of $\mathrm{C}-\mathrm{N}-\mathrm{C}, \mathrm{N}-\mathrm{C}-\mathrm{N}$ and $\mathrm{C}-\mathrm{COO}$ skeletal groups are discussed.
\end{abstract} (C) 2011 Elsevier B.V. All rights reserved.

\section{Introduction}

Great effort has been expended to explore self-assembled organic-organic and organic-inorganic acid-base supramolecular complexes due to their intriguing network topologies, physical and chemical properties and potential applications in the field of material sciences, molecular biology, supramolecular chemistry and the crystal engineering [1-6]. The directional $\mathrm{O}-\mathrm{H} \cdots \mathrm{O}, \mathrm{O}-$ $\mathrm{H} \cdots \mathrm{N}$ and $\mathrm{N}-\mathrm{H} \cdots \mathrm{O}$ or $\mathrm{N}-\mathrm{H} \cdots \mathrm{N}$ interactions resulting from the multiple hydrogen bonds with the neighbours play an important role in molecular recognition and self-assembly of organic or organic-inorganic molecules in solids $[7,8]$. Several materials based on the acid-base ionic and directional hydrogen-bonding interactions exhibit non-linear optical properties due to the relatively strong hyperpolarisability of the base organic part of the crystals [9-17]. Many different self-complementary hydrogen bonding groups can be used to control association in supramolecular chemistry to produce the programmed arrangement, such as chains, sheets, ribbons, tapes and rosettes [18-23].

The commercially available crystalline 2-imino-4-thiobiuret (Scheme 1a, Aldrich, CAS No. 2114-02-05) is in fact the tautomeric form of 1-(diaminomethylene)thiourea (Scheme 1b) as has been identified by the X-ray single crystal analysis [24].

Both tautomers, i.e., 2-imino-4-thiobiuret and 1-(diaminomethylene)thiourea, are potentially interesting compounds as an organic base and useful building blocks in the crystal engineering for

\footnotetext{
* Corresponding author.

E-mail address: j.janczak@int.pan.wroc.pl (J. Janczak).
}

obtaining base-acid materials with extended hydrogen bonds framework, since they contain active hydrogen bonding sites. Additionally, both tautomers can act as $N, N$ - or $N, S$-coordinating ligands forming several types of complexes with metal ions [25-27]. The 1(diaminomethylene)thiourea contains the basic $\mathrm{N}$ atom with the lone-pair of electrons that can accept the proton forming positively charged cations that together with the oppositely charged partners can form salts with the extended hydrogen bonded networks in solids [28-35]. To explore the possibility of the 1-(diaminomethylene)thiourea forming predictable hydrogen-bonding patterns, it would be useful to observe its behaviour towards the other known building blocks like carboxylic acids that are widely used in this context [36]. The crystal engineering of thioureas is still considered to be less developed than that of urea [37]. In the present work, we investigate the crystal structure of 1-(diaminomethylene)thiouron1-ium oxalate by the X-ray single crystal diffraction method. The compound was also characterised by vibrational spectroscopy, and the results are discussed and compared with the data obtained for a neutral 1-(diaminomethylene)thiourea molecule.

\section{Experimental}

All materials were commercially available and used as received. Elemental analysis was carried out with a Perkin-Elmer 240 elemental analyser.

\subsection{Preparation of bis[1-(diaminomethylene)thiouron-1-ium] oxalate}

Commercially available 2-imino-4-thiobiuret (amidinothiourea, Aldrich, CAS No. 2114-02-05), which is in fact the tautomeric form 
<smiles>NN=C(N)N</smiles>

(a)<smiles>NC(=S)N=C(N)N</smiles>

(b)
Scheme 1. 2-Imino-4-thiobiuret (a) and 1-(diaminomethylene)thiourea (b).

1-(diaminomethylene)thiourea and oxalic acid (Aldrich, purity of $99 \%$ ) were added to hot water in a molar proportion of $2: 1$. When the solution became homogeneous it was cooled slowly and kept at room temperature. After several days, transparent colourless crystals were formed. Analysis: calculated for $\mathrm{C}_{6} \mathrm{H}_{14} \mathrm{~N}_{8} \mathrm{O}_{4} \mathrm{~S}_{2}$ : C, 22.44; H, 4.15; N, 34.82; O, 19.25 and S, 19.34\%. Found: C. 22.08; $\mathrm{H}, 4.33$; N, 34.33; O, 19.61 and S, 19.65\%.

\subsection{X-ray data collection}

X-ray intensity data for the crystal were collected using graphite monochromatic MoK $\alpha$ radiation on a four-circle $\kappa$ geometry KUMA KM-4 diffractometer with a two-dimensional area CCD detector. The $\omega$-scan technique with $\Delta \omega=1.0^{\circ}$ for each image was used for data collection. The 930 images for six different runs covering over $99 \%$ of the Ewald sphere were performed. The unit cell parameters were refined by the least-squares methods on the basis of 762 reflections. One image was used as a standard after every 50 images for monitoring of the crystal stability and data collection. No correction on the relative intensity variations was necessary. Data collections were made using the CrysAlis CCD program [38]. Integration, scaling of the reflections, correction for Lorentz and polarisation effects and absorption corrections were performed using the CrysAlis Red program [38]. The structure was solved by the direct methods using SHELXS-97 and refined using SHELXL-97 programs [39]. The hydrogen atoms were located in difference Fourier maps and were refined. The final difference Fourier maps showed no peaks of chemical significance. The largest

Table 1

Crystallographic data for bis[1-(diaminomethylene)thiouron-1-ium] oxalate.

\begin{tabular}{|c|c|}
\hline Empirical formula & $\left(\mathrm{C}_{2} \mathrm{H}_{7} \mathrm{~N}_{4} \mathrm{~S}\right)_{2}\left(\mathrm{C}_{2} \mathrm{O}_{4}\right)$ \\
\hline Formula weight $\left(\mathrm{g} \mathrm{mol}^{-1}\right)$ & 326.38 \\
\hline Crystal system, space group & Monoclinic, $C 2 / c$ (No. 15) \\
\hline$a(\AA)$ & $10.818(2)$ \\
\hline$b(\AA)$ & $12.040(3)$ \\
\hline$c(\AA)$ & $10.710(2)$ \\
\hline$\beta\left(^{\circ}\right)$ & $99.13(1)$ \\
\hline$V\left(\AA^{3}\right)$ & $1377.3(5)$ \\
\hline$Z$ & 4 \\
\hline$D_{\text {calc }} / D_{\text {obs }}\left(\mathrm{g} \mathrm{cm}^{-3}\right)$ & $1.574 / 1.57$ \\
\hline$\mu\left(\mathrm{mm}^{-1}\right)$ & 0.415 \\
\hline Crystal size (mm) & $0.36 \times 0.28 \times 0.24$ \\
\hline Radiation type, wavelength, $\lambda(\AA)$ & Mo K $\alpha, 0.71073$ \\
\hline Temperature (K) & $295(2)$ \\
\hline$\theta$ Range $\left({ }^{\circ}\right)$ & $3.01-29.40$ \\
\hline Absorption correction & Numerical, CrysAlis Red [38] \\
\hline$T_{\min } / T_{\max }$ & $0.8871 / 0.9112$ \\
\hline Reflections collected/unique/observed & $8372 / 1770 / 1400$ \\
\hline$R_{\text {int }}$ & 0.0225 \\
\hline Refinement on & $F^{2}$ \\
\hline$R\left[F^{2}>2 \sigma\left(F^{2}\right)\right]$ & 0.0293 \\
\hline$w R\left(F^{2}\right.$ all reflections $)$ & 0.0730 \\
\hline Goodness-of-fit, $S$ & 1.001 \\
\hline$\Delta \rho_{\max }, \Delta \rho_{\min }\left(\mathrm{e} \AA^{-3}\right)$ & $+0.207,-0.201$ \\
\hline
\end{tabular}

peaks on the final $\Delta \rho$ map were +0.207 and -0.201 e $\AA^{-3}$. Details of the data collection parameters, crystallographic data and final agreement parameters are collected in Table 1. Visualisation of the structure was made with the Diamond 3.0 program [40]. Selected geometrical parameters are listed in Table 2 and the geometry of hydrogen bonding interactions are collected in Table 3.

\subsection{Vibrational spectra measurements}

The vibrational measurements were carried out at room temperature. The Fourier transform infrared spectrum was recorded from nujol mulls between 4000 and $400 \mathrm{~cm}^{-1}$ on a Bruker IFS 113V FTIR. The Fourier Transform Raman spectrum was recorded on a FRA-106 attached to the Bruker 113V FTIR spectrometer equipped with $\mathrm{Ge}$ detector cooled to liquid nitrogen temperature. Resolution was set up to $2 \mathrm{~cm}^{-1}$, signal/noise ratio was established by 32 scans. $\mathrm{Nd}^{3+}$-YAG air-cooled diode pumped laser of power ca. $200 \mathrm{~mW}$ was used as an exciting source. The incident laser excitation was $1064 \mathrm{~nm}$. The scattered light was collected at the angle of $180^{\circ}$ in the region of $3600-80 \mathrm{~cm}^{-1}$, resolution $2 \mathrm{~cm}^{-1}, 256$ scans. Deuterated $\mathrm{D}^{7}$ bis(1-(diaminomethylene)thiouron-1-ium) oxalate was prepared by the usual reaction with heavy water. The crystals

Table 2

Bond lengths $(\AA)$ and angles $\left(^{\circ}\right)$ for bis[1-(diaminomethylene)thiouron-1-ium] oxalate.

\begin{tabular}{llll}
\hline S1-C1 & $1.6708(12)$ & $\mathrm{C} 1-\mathrm{N} 2$ & $1.3229(14)$ \\
$\mathrm{C} 1-\mathrm{N} 1$ & $1.3778(14)$ & $\mathrm{N} 1-\mathrm{C} 2$ & $1.3693(14)$ \\
$\mathrm{C} 2-\mathrm{N} 4$ & $1.3084(15)$ & $\mathrm{C} 2-\mathrm{N} 3$ & $1.3088(14)$ \\
$\mathrm{O} 1-\mathrm{C} 3$ & $1.2501(13)$ & $\mathrm{O} 2-\mathrm{C} 3$ & $1.2435(13)$ \\
C3-C3 & $1.562(2)$ & & \\
N2-C1-N1 & $112.40(10)$ & $\mathrm{N} 2-\mathrm{C} 1-\mathrm{S} 1$ & $121.96(9)$ \\
N1-C1-S1 & $125.64(8)$ & $\mathrm{C} 2-\mathrm{N} 1-\mathrm{C} 1$ & $130.22(9)$ \\
N4-C2-N3 & $120.99(11)$ & $\mathrm{N} 4-\mathrm{C} 2-\mathrm{N} 1$ & $116.11(10)$ \\
N3-C2-N1 & $122.90(10)$ & O2-C3-O1 & $125.83(10)$ \\
O1-C3-C3 & $116.57(11)$ & O2-C3-C3 & $117.59(11)$ \\
\hline
\end{tabular}

Symmetry code: (i) $-x+1 / 2,-y+3 / 2,-z$.

Table 3

Hydrogen-bond geometry $\left(\AA,^{\circ}\right)$.

\begin{tabular}{lllll}
\hline$D-\mathrm{H} \cdots A$ & $D-\mathrm{H}$ & $\mathrm{H} \cdots A$ & $D \cdots A$ & $D-\mathrm{H} \cdots A$ \\
\hline $\mathrm{N} 1-\mathrm{H} 1 \cdots \mathrm{O} 1^{\mathrm{ii}}$ & $0.830(13)$ & $2.068(13)$ & $2.8363(13)$ & $153.7(11)$ \\
$\mathrm{N} 2-\mathrm{H} 21 \cdots \mathrm{O} 1^{\mathrm{ii}}$ & $0.836(13)$ & $2.066(14)$ & $2.8120(15)$ & $148.4(13)$ \\
$\mathrm{N} 2-\mathrm{H} 22 \cdots \mathrm{S} 1^{\mathrm{iii}}$ & $0.851(15)$ & $2.566(15)$ & $3.3801(13)$ & $160.4(11)$ \\
$\mathrm{N} 3-\mathrm{H} 31 \cdots \mathrm{O} 2$ & $0.876(13)$ & $1.974(14)$ & $2.8472(15)$ & $174.2(12)$ \\
$\mathrm{N} 3-\mathrm{H} 32 \cdots \mathrm{S} 1$ & $0.877(15)$ & $2.291(14)$ & $3.0102(13)$ & $139.1(12)$ \\
$\mathrm{N} 4-\mathrm{H} 42 \cdots \mathrm{O} 2^{\text {iv }}$ & $0.847(13)$ & $1.946(14)$ & $2.7726(14)$ & $165.1(13)$ \\
\hline
\end{tabular}

Symmetry codes: (ii) $-x+1 / 2, y-1 / 2,-z-1 / 2$; (iii) $-x+1,-y,-z$; (iv) $x,-y+1$, $z-1 / 2$.

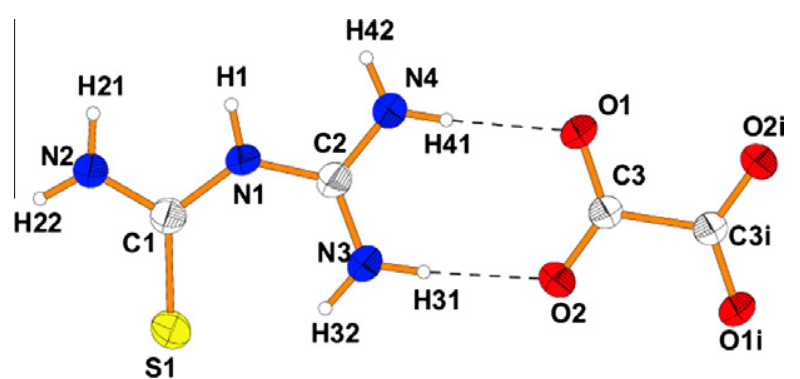

Fig. 1. A view of bis[1-(diaminomethylene)thiouron-1-ium] oxalate showing displacement ellipsoids at the $50 \%$ probability level and $\mathrm{H}$ atoms as a sphere of arbitrary radii. Dashed lines represent the hydrogen bonds. Symmetry code: (i) $-x+1 / 2,-y+3 / 2,-z$. 


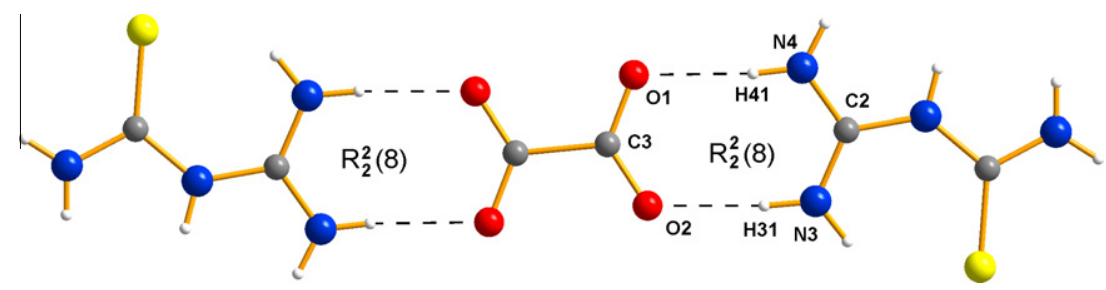

Fig. 2. A view of $\mathrm{R}_{2}^{2}$ (8) hydrogen bonded motifs forming bis[1-(diaminomethylene)thiouron-1-ium] oxalate molecular complex.

of bis(1-(diaminomethylene)thiouron-1-ium) oxalate were dissolved in heavy water, and were left in the atmosphere saturated with heavy water for 1 week in order to avoid the contamination of the crystals. Than the procedure was repeated twice. The obtained deuterated analogue crystallises similar as H-compound in monoclinic system $(C 2 / c)$ with quite similar lattice parameters.

\section{Results and discussion}

Good quality single crystals of bis[1-(diaminomethylene)thiouron-1-ium] oxalate suitable for the X-ray analysis were obtained from water solution at $25^{\circ} \mathrm{C}$. The X-ray single crystal analysis shows that both carboxyl groups of the oxalic acid are deprotonated (Fig. 1). In addition, the X-ray analysis revealed that only a half of the deprotonated oxalate(2-) anion is independent, since it lies on an inversion centre. The oppositely charged units, i.e. 1(diaminomethylene)thiouron-1-ium cation and oxalate anion interact via two pairs of almost linear $\mathrm{N}-\mathrm{H}$...O hydrogen bonds with a graph of $\mathrm{R}_{2}^{2}$ (8) forming almost planar bis[1-(diaminomethylene)thiouron-1-ium] oxalate molecular complex (Fig. 2).

The 1-(diaminomethylene)thiouron-1-ium cation in the crystal is not strictly planar, but twisted. Both arms of the cation are oppositely rotated around the $\mathrm{C}-\mathrm{N}$ bonds involving the central $\mathrm{N} 1$ atom (Fig. 1). The dihedral angle between the $\mathrm{N} 1 / \mathrm{C} 1 / \mathrm{S} 1 / \mathrm{N} 2$ and $\mathrm{N} 1 / \mathrm{C} 2 /$ $\mathrm{N} 3 / \mathrm{N} 4$ planes is $5.0(1)^{\circ}$. The rotation of the arms around the $\mathrm{C}-\mathrm{N}$ bonds in the present structure is significantly smaller than that in the crystal of neutral 1-(diaminomethylene)thiourea molecule
Table 4

The dihedral angle between the arms of the 1-(diaminomethylene)thiouron-1-ium cation in the known salts.

\begin{tabular}{|c|c|c|}
\hline Compounds & $\begin{array}{l}\text { Angle } \\
\left({ }^{\circ}\right)\end{array}$ & Reference \\
\hline Bis[1-(diaminomethylene)thiouron-1-ium] oxalate & $5.0(1)$ & This work \\
\hline 1-(Diaminomethylene)thiouron-1-ium chloride & $22.9(1)$ & {$[28]$} \\
\hline 1-(Diaminomethylene)thiouron-1-ium bromide & $15.2(1)$ & {$[28]$} \\
\hline 1-(Diaminomethylene)thiouron-1-ium iodide & $4.2(1)$ & {$[28]$} \\
\hline 1-(Diaminomethylene)thiouron-1-ium chlorate(VII) & $1.4(1)$ & [29] \\
\hline $\begin{array}{l}\text { 1-(Diaminomethylene)thiouron-1-ium hydrogen } \\
\text { sulphate }\end{array}$ & $9.8(1)$ & [29] \\
\hline $\begin{array}{l}\text { 1-(Diaminomethylene)thiouron-1-ium dihydrogen } \\
\text { phosphonate }\end{array}$ & $4.4(1)$ & [29] \\
\hline $\begin{array}{l}\text { 1-(Diaminomethylene)thiouron-1-ium dihydrogen } \\
\text { arsenate }\end{array}$ & $2.1(1)$ & [29] \\
\hline 1-(Diaminomethylene)thiouron-1-ium nitrate & $7.2(1)$ & {$[30]$} \\
\hline $\begin{array}{l}\text { 1-(Diaminomethylene)thiouron-1-ium phosphonate } \\
\text { monohydrate }\end{array}$ & $3.7(1)$ & {$[30]$} \\
\hline 1-(Diaminomethylene)thiouron-1-ium formate & $5.5(2)$ & {$[33]$} \\
\hline $\begin{array}{l}\text { Bis[1-(diaminomethylene)thiouron-1-ium] oxalate } \\
\text { dihydrate }\end{array}$ & $4.5(2)$ & [33] \\
\hline 1-(Diaminomethylene)thiouron-1-ium picrate & $1.3(1)$ & [34] \\
\hline Bis[1-(diaminomethylene)thiouron-1-ium] fumarate & $13.8(1)$ & [35] \\
\hline 1-(Diaminomethylene)thiourea, ab initio calculations & 6.2 & {$[28]$} \\
\hline 1-(Diaminomethylene)thiourea, in the crystal & $22.2(1)$ & {$[24]$} \\
\hline
\end{tabular}

$\left(22.2(1)^{\circ}\right)$ [24]. The gas-phase conformation of 1-(diaminomethylene)thiouron-1-ium cation as show by ab initio MO calculations is also twisted, with a dihedral angle of $6.2^{\circ}$ [28]. The currently

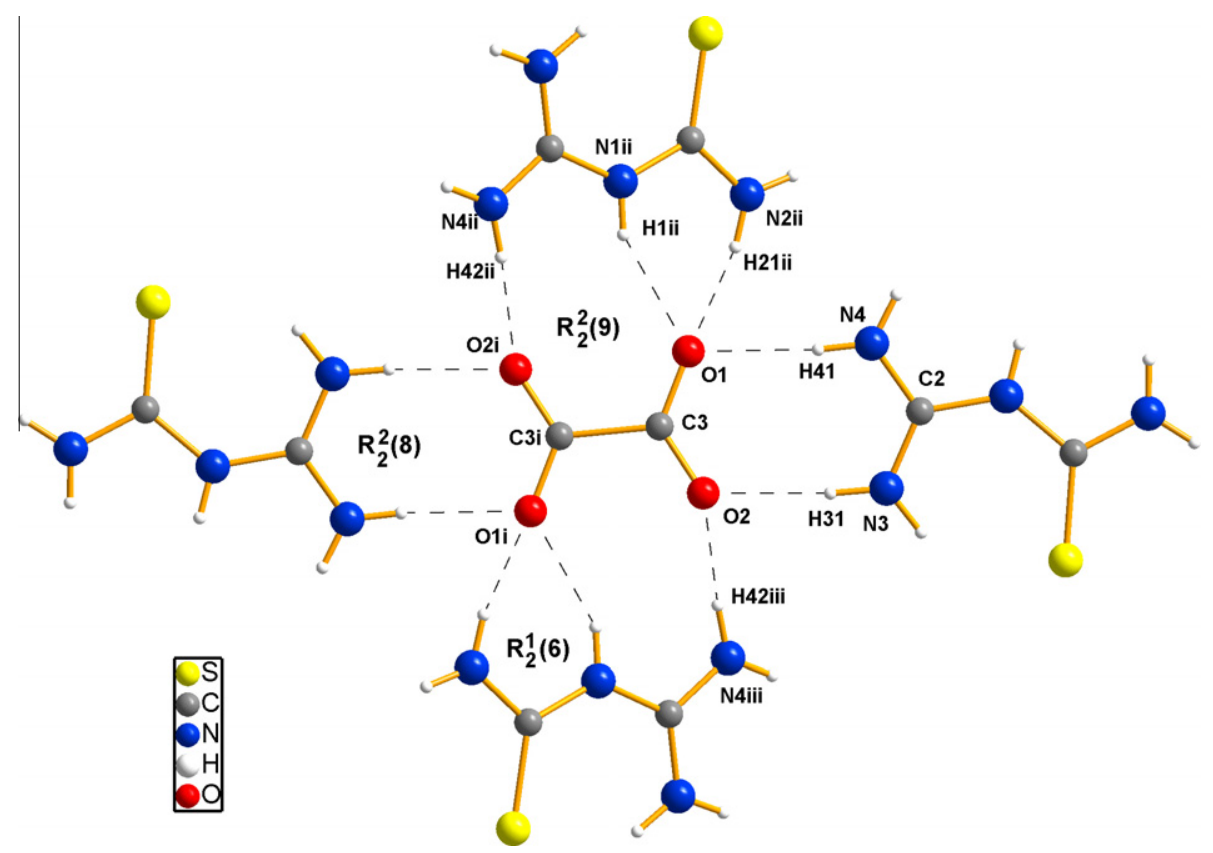

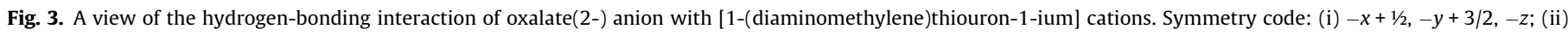
$-x+1 / 2, y+1 / 2,-z-1 / 2$; (iii) $x,-y+1, z+1 / 2$. 

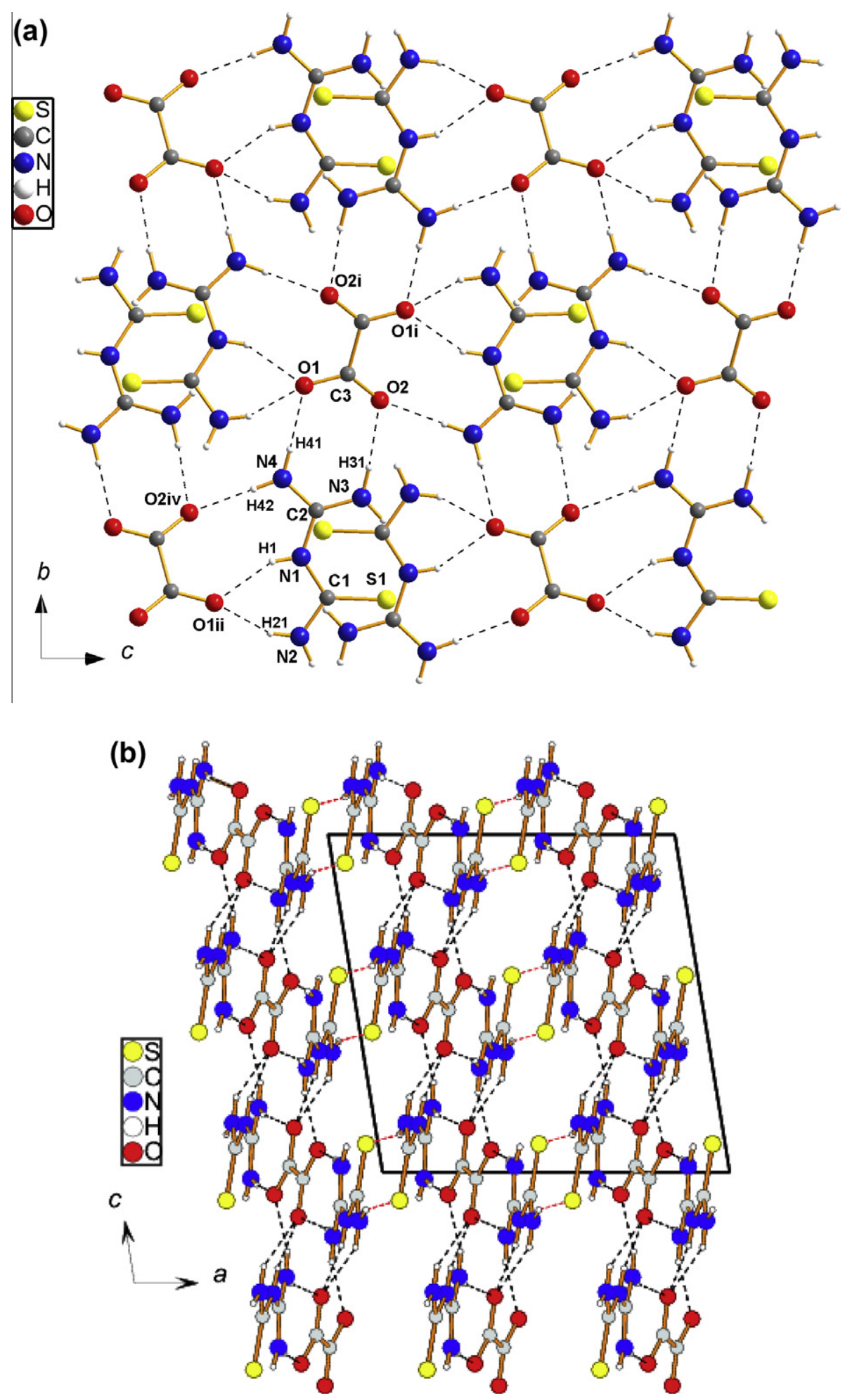

Fig. 4. A view along $a$-axis of 2D-layer (a) and the crystal packing of bis[1-(diamino-methylene)thiouron-1-ium] oxalate in the unit cell (b).

available data on 1-(diaminomethylene)thiouron-1-ium salts show that the cation twisting may differ when different anions are used (Table 4) and is undoubtedly dependent on the hydrogen bonding system formed by the oppositely charged units. Protonation of the 1-(diaminomethylene)thiourea molecule causes a decrease of the steric effect of the lone-pairs of electrons at the S1 atom, and in result reduces the dihedral angle between the arms of the cation, when compared with that of neural 1-(diaminomethylene)thiourea molecule [22]. The C1-S1 bond (Table 2) is slightly longer than the typical $\mathrm{C}=\mathrm{S}$ double bond as observed in the thioformaldehyde $\mathrm{CH}_{2} \mathrm{C}=\mathrm{S}(1.6019(8) \AA$ ) [41], which represents $100 \%$ double-bond character, and is slightly shorter than the value of $\sim 1.74 \AA$ as observed in several thiolate anions that represents $50 \%$ double-bond character [42]. Thus the bond order of the $\mathrm{C} 1-\mathrm{S} 1$ bond is intermediate between the 2 and 1.5. The three $\mathrm{C}-\mathrm{NH}_{2}$ bond distances are in the range of $1.3084(15)-1.3229(14) \AA$, are thus shorter than typical 

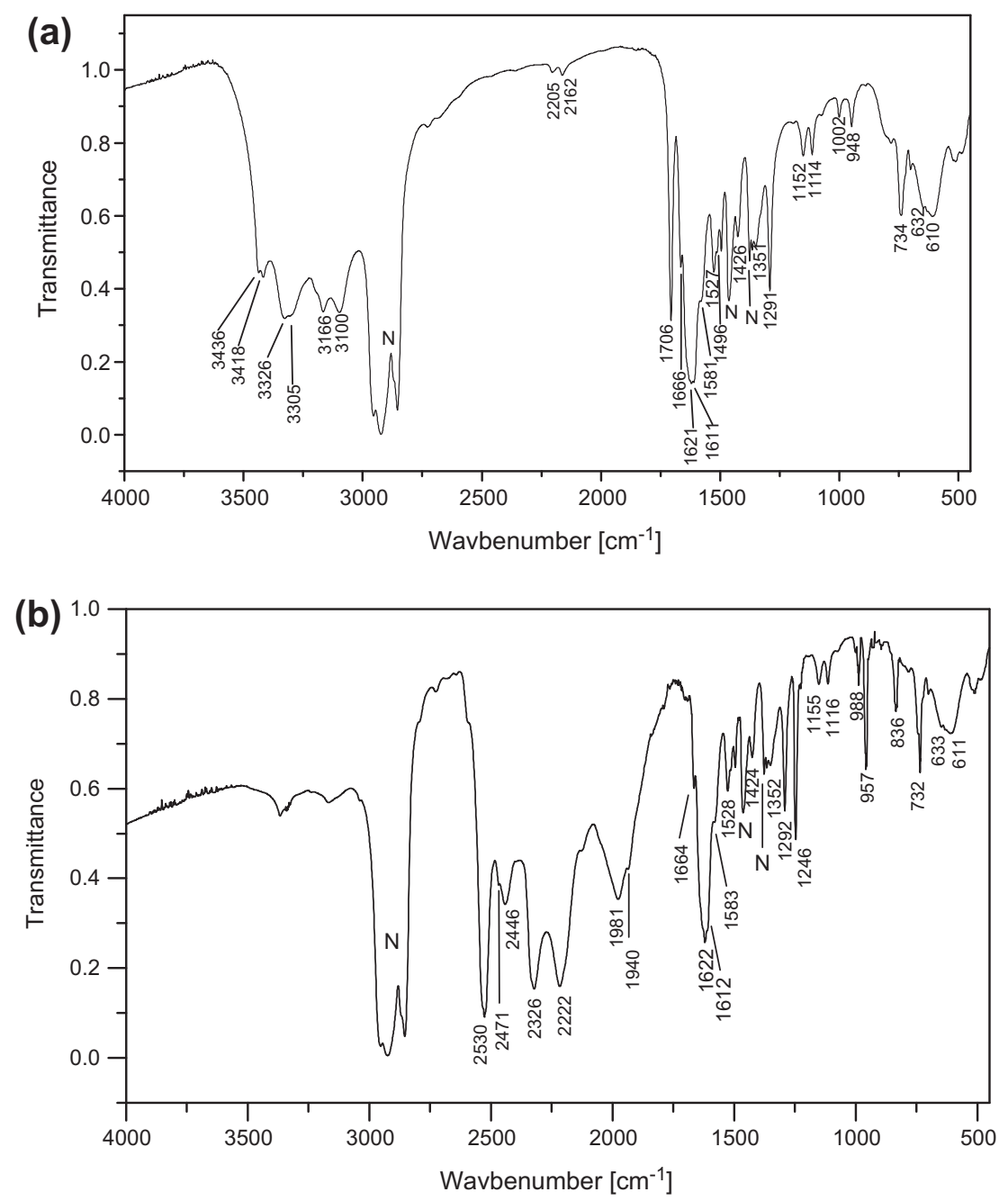

Fig. 5. Room temperature FTIR spectrum of bis[1-(diaminomethylene)thiouron-1-ium] oxalate (a) and its deuterated analogue (b).

single bond $\mathrm{C}\left(\mathrm{sp}^{2}\right)-\mathrm{NH}_{2}$ of $1.341-1.363 \AA$ [ [43]. The central N1 atom links both arms of the 1-(diaminomethylene)thiouron-1-ium cation by a shorter bond to atom C2 (1.3693(14) $\AA$ ) and a longer bond to atom $\mathrm{C} 1$ (1.3778(14) $\AA$ ). However, both $\mathrm{C}-\mathrm{N}$ bonds involving the central $\mathrm{N} 1$ atom are significantly longer than the three $\mathrm{C}-\mathrm{NH}_{2}$ bonds linking the amine groups (Table 2). The planarity of the amine groups points to the $\mathrm{sp}^{2}$ hybridisation of the orbitals on the amine nitrogen atoms. This indicates that the lone pair of electrons occupies the p orbital that is perpendicular to the plane of $\mathrm{NH}_{2}$ group. Additionally, the p orbitals of the $\mathrm{C}, \mathrm{S}$ and $\mathrm{N}$ atoms forming the $\pi$ bond of the C1-S1 and C2-N1 double bonds as observed in neutral molecule (see Scheme 1) are also perpendicular to the plane. Therefore due to symmetry of the p orbitals the partial delocalisation of $\pi$ bonds is possible and leads to the elongation of the double $\mathrm{C} 1=\mathrm{S} 1$ and $\mathrm{C} 2=\mathrm{N} 1$ bonds and to shortening of other $\mathrm{C}-\mathrm{N}$ bonds linking the amine groups (Table 2). Thus the bond order of the $\mathrm{C}-\mathrm{NH}_{2}$ bonds is greater than of the both $\mathrm{C}-\mathrm{N}$ bonds involving the central $\mathrm{N} 1$ atom.

The geometric parameters of the oxalate(2-) anion do not deviate significantly from the reported values in the other oxalate structures [44]. However, the C-C bond length of $1.562(2) \AA$ is slightly longer than that in the crystal structure of oxalic acid, 1.525(3) $\AA$ [45]. The oxalate(2-) anion, as in the most of the available structures, is flat and centrosymmetric. However, there are also known the cases of the twisted oxalate anion as in 4-ammonium-1-methylpiperazinium oxalate dihydrate [46] or in bis(2-hydroxy-2-butyl)ethylene- diammonium oxalate pentahydrate [47] with a twisting angle of $18.9(2)^{\circ}$ and $44.2(2)^{\circ}$, respectively.

The hydrogen-bonding pattern involving the oxalate(2-) anion consists of three pairs of different hydrogen-bonding motifs. One of them is $R_{2}^{2}$ (8) that is formed by donation to the oxalate(2-) anion from two amine groups of 1-(diaminomethylene)thiouron-1ium cation bonded to the $\mathrm{C} 2$ atom. The $\mathrm{N}-\mathrm{H} \cdots \mathrm{O}$ hydrogen bonds forming the $\mathrm{R}_{2}^{2}(8)$ motifs are almost linear and join the oxalate(2) anion with two 1-(diaminomethylene)thiouron-1-ium cations forming almost planar bis[1-(diaminomethylene)thiouron-1-ium] oxalate molecular complex (Fig. 2). The other two motifs, $R_{2}^{2}(9)$ and $R_{2}^{1}(6)$, link the oxalate(2-) anion with two 1-(diaminomethylene)thiouron-1-ium cations that are inclined by $\sim 27^{\circ}$ to the average plane of bis[1-(diaminomethylene)thiouron-1-ium] oxalate molecular complex (Fig. 3 ). The $\mathrm{R}_{2}^{2}(8)$ motif involve the oxygen atoms of one carboxylate group, while the other $R_{2}^{2}(9)$ motif involve the oxygen atoms of both carboxylate groups. The $R_{2}^{1}(6)$ motif involves two hydrogen bonds with the central imine N1 atom and the amine group joined to the thiolate carbon atom (C1) and only one oxygen atom of carboxyl group. These $\mathrm{N}$ $\mathrm{H}$...O hydrogen bonds are robust enough to retain the environment of the oxalate(2-) anion stabilising the supramolecular structure (Fig. 3). The supramolecular architecture presented in Fig. 3 interacts with the neighbour via $\mathrm{N}-\mathrm{H} \ldots \mathrm{O}$ hydrogen bonds of amine group (N4) forming pseudo-two dimensional layer parallel to the $b c$-plane (Fig. $4 \mathrm{a}$ ). 


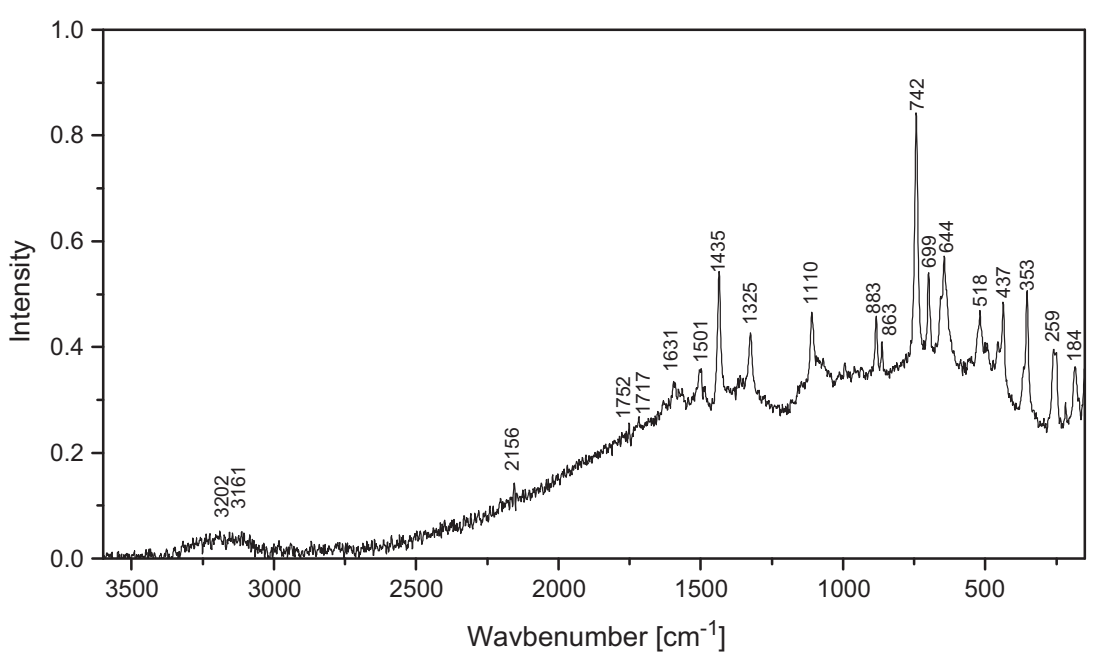

Fig. 6. Raman spectrum of bis[1-(diaminomethylene)thiouron-1-ium] oxalate.

The presence of the sulphur atom in the 1-(diaminomethylene)thiouron-1-ium cation raises the question of whether there are hydrogen bonds with the $\mathrm{S}$ as an acceptor, although the importance of such interactions has been questioned [48]. Nevertheless, there are authors motivated by the high content of sulphur in biological systems who claim to utilise the D-H..S interactions ( $\mathrm{D}=$ donor) in the crystal engineering. The $\mathrm{N}-\mathrm{H} \cdots \mathrm{S}$ interactions have been utilised for design supramolecular arrangement of thiourea derivatives [49]. Thus such N-H..S intramolecular interactions seem to be present in the bis[1(diaminomethylene)thiouron-1-ium] oxalate structure (Table 3). Besides, the $\mathrm{N}-\mathrm{H} \ldots \mathrm{S}$ intramolecular interactions, the $\mathrm{N}-\mathrm{H} \ldots \mathrm{S}$ intermolecular interactions in the present structure are also exist. These $\mathrm{N}-\mathrm{H} \cdots \mathrm{S}$ intermolecular interactions link the 2D-layers forming a three-dimensional network (Fig. 4b).

The FT-IR spectra of bis[1-(diaminomethylene)thiouron-1-ium] oxalate and its deuterated analogue are shown in Fig. 5a and b, respectively, while the Raman for the protiated complex is given in Fig. 6. The bands corresponding to the vibration of the functional groups were identified with the aid of infrared correlation charts [50-52]. In addition, the spectra of bis[1-(diaminomethylene)thiouron-1-ium] oxalate are compared with the spectra of 1-(diaminomethylene)thiourea [34] and of oxalic acid [53,54] as well as of oxalates [55-57]. The title compound has several functional and skeletal groups such as three $\mathrm{NH}_{2}, \mathrm{C}=\mathrm{S}, \mathrm{C}-\mathrm{N}-\mathrm{C}, \mathrm{N}-\mathrm{C}-\mathrm{N}$ and $\mathrm{N}-\mathrm{C}-\mathrm{S}$ groups in the cation and $\mathrm{COO}^{-}, \mathrm{C}-\mathrm{C}, \mathrm{C}-\mathrm{COO}^{-}, \mathrm{C}-\mathrm{C}-\mathrm{C}$ and $\mathrm{C}-\mathrm{H}$ in the anion. A careful inspection of the IR spectrum (Fig. 5a) shows medium-strong intensity bands in the spectral range of 3436 and $3100 \mathrm{~cm}^{-1}$ that can be attributed to the asymmetric and symmetric stretching of three $\mathrm{NH}_{2}$ groups of the 1-(diaminomethylene)thiouron-1-ium cation. In the Raman spectrum the bands of $v \mathrm{NH}_{2}$ stretching vibrations appear in the $3400-3000 \mathrm{~cm}^{-1}$ region as a very weak one. These bands, as expected, are shifted in the IR spectrum of deuterated analogue (Fig. 5b) to the spectral region of $2530-2220 \mathrm{~cm}^{-1}$. The strong narrow band at $1709 \mathrm{~cm}^{-1}$ in the IR spectrum is assigned to the stretching of imine bond of the cation, since a similar band is observed in some imines and their slats [58]. Its Raman counterpart is localised at $1717 \mathrm{~cm}^{-1}$ as a weak band (Fig. 6). In addition, the band of imine group of the deuterated analogue is shifted, as expected, to the $1246 \mathrm{~cm}^{-1}$ (Fig. 5b). The X-ray data reveal that the all $\mathrm{NH}_{2}$ groups of 1-(diaminomethylene)thiouron-1-ium cation are involved in the $\mathrm{N}-\mathrm{H} \ldots$. O hydrogen bonds with $\mathrm{N}$. . O distances ranging from 2.7726(14) to 2.8472(15) A. This reveals as a broad band in the range of $3300-2500 \mathrm{~cm}^{-1}$, which is shifted to $\sim 1950 \mathrm{~cm}^{-1}$ in the spectrum of deuterated analogue. Additionally, the broad band in the region of $1400-1100 \mathrm{~cm}^{-1}$ that overlaps with $v(\mathrm{C}-\mathrm{N})$ of the cation points the presence of the $\mathrm{N}-\mathrm{H} \cdots \mathrm{O}$ hydrogen bonds. The $v_{\mathrm{a}}\left(\mathrm{CO}_{2}^{-}\right)$ and $v_{\mathrm{s}}\left(\mathrm{CO}_{2}^{-}\right)$bands of oxalate(2-) anion in the IR spectrum of bis[1(diaminomethylene)thiouron-1-ium] oxalate are observed at 1621 and $1527 \mathrm{~cm}^{-1}$, respectively, which are also present and unchanged in the spectrum of deuterated analogue (Fig. 5b). The $v_{\mathrm{a}}\left(\mathrm{CO}_{2}^{-}\right)$mode give rises to the absorption at $1631 \mathrm{~cm}^{-1}$, while the $v_{\mathrm{s}}\left(\mathrm{CO}_{2}^{-}\right)$vibrational mode is observed as weak band at $1501 \mathrm{~cm}^{-1}$ in the Raman spectrum. The $v(\mathrm{C}=\mathrm{S})$ band of the 1-(diaminomethylene)thiouron1-ium cation, similar as in thiourea, is observed at $\sim 730 \mathrm{~cm}^{-1}$ in

Table 5

FT IR and Raman spectral data for bis[1-(diaminomethylene)thiouron-1-ium] oxalate.

\begin{tabular}{|c|c|c|}
\hline $\begin{array}{l}\text { Infrared, } v \\
\left(\mathrm{~cm}^{-1}\right)\end{array}$ & $\begin{array}{l}\text { Raman, } v \\
\left(\mathrm{~cm}^{-1}\right)\end{array}$ & Assignment \\
\hline $3436 \mathrm{~m}$ & & $v_{\mathrm{a}}\left(\mathrm{NH}_{2}\right)$ asym stretch \\
\hline $3418 \mathrm{~m}$ & & $v_{\mathrm{a}}\left(\mathrm{NH}_{2}\right)$ asym stretch \\
\hline $3326 \mathrm{~m}$ & $3202 v w$ & $v_{\mathrm{a}}\left(\mathrm{NH}_{2}\right)$ asym stretch \\
\hline $3305 \mathrm{~m}$ & & $v_{\mathrm{s}}\left(\mathrm{NH}_{2}\right)$ sym stretch \\
\hline $3166 \mathrm{~m}$ & $3161 v w$ & $v_{\mathrm{s}}\left(\mathrm{NH}_{2}\right)$ sym stretch \\
\hline $3100 \mathrm{~m}$ & & $v_{\mathrm{s}}\left(\mathrm{NH}_{2}\right)$ sym stretch \\
\hline $\begin{array}{c}\text { Broad band } \\
\sim 2700\end{array}$ & & $\mathrm{~N}-\mathrm{H} \cdots \mathrm{O}$ hydrogen bonds \\
\hline $1706 s$ & $1717 w$ & Imine bond stretch \\
\hline $1666 \mathrm{~m}$ & & $v_{\mathrm{a}}\left(\mathrm{CO}_{2}^{-}\right)$ \\
\hline $1621 s$ & $1631 w$ & $v_{\mathrm{a}}\left(\mathrm{CO}_{2}^{-}\right)$ \\
\hline \multicolumn{3}{|l|}{$1611 \mathrm{~s}$} \\
\hline \multicolumn{3}{|l|}{$1581 \mathrm{~m}$} \\
\hline $1527 \mathrm{~m}$ & $1501 w$ & $\begin{array}{l}v_{\mathrm{s}}\left(\mathrm{CO}_{2}^{-}\right) \text {overlapped with } \delta\left(\mathrm{NH}_{2}\right) \text { asym } \\
\text { def. }\end{array}$ \\
\hline $1496 \mathrm{~m}$ & $1435 \mathrm{~m}$ & $v(\mathrm{C}-\mathrm{N})$ \\
\hline 1426w & & $\gamma(\mathrm{C}-\mathrm{C})$ overlapped with nujol \\
\hline $1351 w$ & $1325 \mathrm{~m}$ & $v(\mathrm{C}-\mathrm{N})$ overlapped with nujol \\
\hline $1291 \mathrm{~m}$ & & $\delta\left(\mathrm{NH}_{2}\right)$ \\
\hline $1152 w$ & & $\delta\left(\mathrm{NH}_{2}\right)$ \\
\hline $1114 w$ & $1110 \mathrm{~m}$ & $\gamma\left(\mathrm{NH}_{2}\right)$ \\
\hline \multicolumn{3}{|l|}{$1002 w$} \\
\hline \multirow[t]{2}{*}{$948 m$} & & $\gamma(\mathrm{C}-\mathrm{N})$ \\
\hline & $883 \mathrm{~m}$ & $\delta(\mathrm{O}-\mathrm{C}-\mathrm{O})$ overlapped with $v(\mathrm{C}-\mathrm{C})$ \\
\hline $785 w$ & $863 w$ & $\gamma(\mathrm{C}-\mathrm{C})$ \\
\hline \multirow[t]{2}{*}{$734 \mathrm{~m}$} & $742 \mathrm{vs}$ & $v(\mathrm{C}=\mathrm{S})$ \\
\hline & $699 \mathrm{~m}$ & \\
\hline $632 \mathrm{~m}$ & $644 \mathrm{~m}$ & $\tau\left(\mathrm{NH}_{2}\right), \omega\left(\mathrm{NH}_{2}\right)$ \\
\hline $610 \mathrm{~m}$ & & Skeletal C-N-C, N-C-N \\
\hline $532 \mathrm{~m}$ & & Skeletal C-N-C, N-C-N \\
\hline \multirow[t]{5}{*}{$512 w$} & $518 \mathrm{~m}$ & $\delta(\mathrm{C}-\mathrm{COO})$ \\
\hline & $437 \mathrm{~m}$ & $\gamma(\mathrm{C}-\mathrm{COO})$ \\
\hline & $353 \mathrm{~m}$ & $\delta(\mathrm{CS})$ \\
\hline & $259 \mathrm{~m}$ & Skeletal C-N-C, N-C-N \\
\hline & $184 \mathrm{~m}$ & \\
\hline
\end{tabular}


Table 6

FT IR spectral data for deuterated bis[1-(diaminomethylene)thiouron-1-ium] oxalate.

\begin{tabular}{|c|c|}
\hline Infrared, $v\left(\mathrm{~cm}^{-1}\right)$ & Assignment \\
\hline 2530s & $\mathrm{ND}_{2}$ asym stretch \\
\hline $2471 \mathrm{~m}$ & $\mathrm{ND}_{2}$ asym stretch \\
\hline $2446 \mathrm{~m}$ & $\mathrm{ND}_{2}$ sym stretch \\
\hline $2326 \mathrm{~m}$ & $\mathrm{ND}_{2}$ sym stretch \\
\hline $2222 \mathrm{~m}$ & $\mathrm{ND}_{2}$ sym stretch \\
\hline $1977 \mathrm{~m}$ & $\mathrm{~N}-\mathrm{D} \cdots \mathrm{O}$ \\
\hline $1937 \mathrm{~m}$ & $\mathrm{~N}-\mathrm{D} \cdots \mathrm{O}$ \\
\hline $1664 \mathrm{~m}$ & $v_{\mathrm{a}}\left(\mathrm{CO}_{2}^{-}\right)$ \\
\hline $1622 s$ & $v_{\mathrm{a}}\left(\mathrm{CO}_{2}^{-}\right)$ \\
\hline \multicolumn{2}{|l|}{$1612 \mathrm{~s}$} \\
\hline $1583 \mathrm{~m}$ & $v(\mathrm{C}-\mathrm{N}), v(\mathrm{C}-\mathrm{C})$ overlapped with nujol \\
\hline $1528 w$ & $v_{\mathrm{s}}\left(\mathrm{CO}_{2}^{-}\right)$overlapped with nujol \\
\hline $1424 w$ & $\gamma(\mathrm{C}-\mathrm{C})$ overlapped with nujol \\
\hline $1352 w$ & $v(\mathrm{C}-\mathrm{N})$ overlapped with nujol \\
\hline $1292 \mathrm{~m}$ & $v(\mathrm{C}-\mathrm{N})$ \\
\hline $1246 \mathrm{~m}$ & Imine bond stretch (ND) \\
\hline \multicolumn{2}{|l|}{$1155 w$} \\
\hline \multicolumn{2}{|l|}{ 1116w } \\
\hline 988w & $\mathrm{ND}_{2}$ rocking \\
\hline $957 \mathrm{~m}$ & $v(\mathrm{C}-\mathrm{N}), \delta\left(\mathrm{ND}_{2}\right)$ \\
\hline $836 w$ & $\gamma\left(\mathrm{ND}_{2}\right)$ \\
\hline $732 \mathrm{~s}$ & $v(\mathrm{C}=\mathrm{S})$ \\
\hline $633 \mathrm{~m}$ & Skeletal C-N-C, N-C-N \\
\hline $611 \mathrm{~m}$ & Skeletal C-N-C, N-C-N \\
\hline $531 w$ & Skeletal C-N-C, N-C-N \\
\hline $511 w$ & $\delta(\mathrm{C}-\mathrm{COO})$ \\
\hline
\end{tabular}

both IR and Raman spectrum, while in several thiourea metal complexes the $v(\mathrm{C}=\mathrm{S})$ band is observed in the range $715-700 \mathrm{~cm}^{-1}[59]$. The band of the $v(\mathrm{C}=\mathrm{S})$ mode is observed in the deuterated sample spectrum at almost the same frequency (Fig. 5b). The observed frequencies of the most prominent bands and their assignments are listed in the Tables 5 and 6.

\section{Conclusion}

The single crystals of bis[1-(diaminomethylene)thiouron-1ium] oxalate were grown using a solution growth technique. The oppositely charged units, i.e. 1-(diaminomethylene)thiouron-1ium cation and oxalate anion interact via two pairs of almost linear $\mathrm{N}-\mathrm{H} \ldots \mathrm{O}$ hydrogen bonds with a graph of $\mathrm{R}_{2}^{2}(8)$ forming almost planar bis[1-(diaminomethylene)thiouron-1-ium] oxalate molecular complex. This complex interacts via two another graphs of $R_{2}^{1}$ (6) and $R_{2}^{2}$ (9) stabilising the environment of the oxalate(2-) anion. The arrangement of these oppositely charged units in the crystal is mainly determined by the ionic attraction forces and the $\mathrm{N}-\mathrm{H} \cdots \mathrm{O}$ hydrogen bonds forming three-dimensional network. Comparison of the IR spectra of bis[1-(diaminomethylene)thiouron-1-ium] oxalate and its deuterated analogue clearly shows marked differences in the regions of vibrations of the amine and imine groups as well as in the region of the $\mathrm{N}-\mathrm{H} \ldots \mathrm{O}$ hydrogen bonds.

\section{Appendix A. Supplementary material}

Additional material comprising full details of the X-ray data collection and final refinement parameters including anisotropic thermal parameters and full list of the bond lengths and angles have been deposited with the Cambridge Crystallographic Data Center in the CIF format as supplementary publications no. CCDC 835127. Copies of the data can be obtained free of charge on the application to CCDC, 12 Union Road, Cambridge, CB21EZ, UK, (fax: +44 1223336 033; email: deposit@ccdc.cam.ac.uk). Supplementary data associated with this article can be found, in the online version, at doi:10.1016/j.molstruc.2011.10.020.

\section{References}

[1] J.C. MacDonald, G.R. Whitesides, Chem. Rev. 94 (1994) 2382.

[2] A.D. Burrows, C.W. Chann, M.M. Chowdhy, J.E. McGrady, D.M.P. Mingos, Chem. Soc. Rev. 24 (1995) 329.

[3] G.R. Desiraju, T. Steiner, The Weak Hydrogen Bond in Structural Chemistry and Biology, Oxford University Press, Oxford, 1999.

[4] A. Nangia, Curr. Opin. Solid State Mater. Sci. 5 (2001) 115.

[5] M. Moulton, M. Zaworotko, Chem. Rev. 101 (2001) 1629.

[6] G.R. Desiraju, Acc. Chem. Res. 35 (2002) 565

[7] G.M. Whitesides, E.E. Simanek, J.P. Mathias, C.T. Seto, D.N. Chin, M. Mammen, D.M. Gordon, Acc. Chem. Res. 28 (1995) 37.

[8] T. Steiner, Angew. Chem. Int. Ed. Engl. 41 (2002) 48.

[9] S. Ghattacharya, P. Dastidar, T.N.G. Row, Chem. Mater. 6 (1994) 531.

[10] J.M. Lehn, Proc. Ind. Acad. Sci. (Chem. Sci.) 106 (1994) 915.

[11] R.G. Xiang, C.M. Liu, G.L. Da, W. Hong, X.Z. You, Polyhedron 16 (1997) 1263.

[12] N. Blagden, K.R. Seddon, Cryst. Eng. 2 (1999) 9.

[13] T. Głowiak, S. Debrus, M. May, A.J. Barnes, H. Ratajczak, J. Mol. Struct. 596 (2001) 77.

[14] M. Marchewka, J. Janczak, S. Debrus, J. Baran, H. Ratajczak, Solid State Sci. 5 (2003) 643.

[15] G.J. Perpétuo, J. Janczak, Acta Cryst. C62 (2006) 0372

[16] M. Jaya Prakash, T.P. Radhakrishnan, Chem. Mater. 18 (2006) 2943.

[17] J. Janczak, G.J. Perpétuo, Solid State Sci. 11 (2009) 1576.

[18] M.C.T. Fyfe, J.F. Stoddart, Acc. Chem. Res. 30 (1997) 393.

[19] A.G. Bielejewska, C.E. Marjo, L.J. Prins, P. Timmerman, F. De Jong, D.N Reinhoudt, J. Am. Chem. Soc. 123 (2001) 7518.

[20] S. Yagai, T. Nakajima, K. Kishikawa, S. Kohmoto, T. Karatsu, A. Kitamura, J. Am. Chem. Soc. 127 (2005) 11134.

[21] N. Sakai, Y. Kamikawa, M. Nishii, T. Matsuoka, T. Kato, S. Matile, J. Am. Chem. Soc. 128 (2006) 2218.

[22] C. Valles, C. Drummond, H. Saadaoui, C.A. Furado, M. He, O. Roubeau, L. Ortolani, M. Monthioux, A. Penicaud, J. Am. Chem. Soc. 130 (2008) 15802.

[23] X. Zhu, X.G. Liu, B.L. Li, Y. Zhang, CrystEngComm 11 (2009) 997.

[24] J. Janczak, G.J. Perpétuo, Acta Cryst. C64 (2008) o114.

[25] K. Chakrabarty, T. Kar, S.P.S. Gupta, Acta Cryst. C46 (1990) 2065.

[26] M.K. Kabir, K. Yamada, K. Adachi, M. Kondo, S. Kawata, Acta Cryst. C58 (2002) m580.

[27] E. Doxiadi, R. Vilar, A.J.P. White, D.J. Williams, Polyhedron 22 (2003) 2991.

[28] G.J. Perpétuo, J. Janczak, Acta Cryst. C64 (2008) o264.

[29] J. Janczak, G.J. Perpétuo, Acta Cryst. C64 (2008) 0330.

[30] J. Janczak, G.J. Perpétuo, Acta Cryst. C65 (2009) 0118.

[31] M. Hołyńska, M. Kubiak, Acta Cryst. C64 (2008) 0609.

[32] M. Hołyńska, M. Kubiak, Acta Cryst. C65 (2009) 0191.

[33] M. Hołyńska, M. Kubiak, Acta Cryst. C65 (2009) 0410.

[34] J. Janczak, G.J. Perpétuo, J. Mol. Struct. 975 (2010) 166.

[35] J. Janczak, G.J. Perpétuo, J. Mol. Struct. 988 (2011) 73.

[36] T. Steiner, Acta Cryst. B57 (2001) 103.

[37] R. Custelcean, Chem. Commun. (2001) 295.

[38] CrysAlis CCD and CrysAlis Red, Version 171.32.6, Oxford Diffraction Poland Wrocław, Poland, 2006.

[39] G.M. Sheldrick, SHELXS97, SHELXL97, Programs for Crystal Structures Solution and Refinement, University of Göttingen, Göttingen, Germany, 1997.

[40] K. Brandenburg, H. Putz, DIAMOND Version 3.0, Crystal Impact GbR, Bonn, Germany, 2006.

[41] D.R. Johnson, F.X. Powell, W.H. Kirchoff, J. Mol. Spectrosc. 39 (1971) 36

[42] R. Fausto, L.A.E. Batista de Carvalho, J.J.C. Teixeria-Dias, M.N. Ramos, J. Chem. Soc. Perkin Trans. 2 (1989) 1945.

[43] F.H. Allen, O. Kennard, D.G. Watson, L. Brammer, A.G. Orpen, R. Taylor, J. Chem. Soc. Perkin Trans. 2 (1989) S1-S19.

[44] F.H. Allen, Acta Cryst. B58 (2002) 380.

[45] J.L. Derissen, P.H. Smith, Acta Cryst. B30 (1974) 2240.

[46] V.R. Thalladi, M. Nüsse, R. Boese, J. Am. Chem. Soc. 122 (2000) 9227.

[47] M.L. Guo, Acta Cryst. E60 (2004) 0576.

[48] G.Y. Bai, H.S. Ning, J. Simpson, X.Y. Qin, N. Li, Acta Cryst. E62 (2006) o4567.

[49] F.H. Allen, C.H. Bird, R.S. Rowland, P.R. Raithby, Acta Cryst. B53 (1997) 696

[50] J. Valdez-Martinez, S. Hernandez-Ortega, M. Rubio, D.T. Li, J.K. Swearingen, W. Kaminsky, D.R. Kelman, D.X. West, J. Chem. Crystallogr. 34 (2004) 535.

[51] G. Socrates, Infrared Characteristic Group Frequencies;, Wiley-Interscience, Chichester, UK, 1980.

[52] G. Socrates, Infrared and Raman Characteristic Group Frequencies, third ed., Wiley, New York, USA, 2001

[53] M.F. Collins, B.C. Haywood, J. Chem. Phys. 52 (1970) 5740.

[54] J. Adams, H. Kim, Spectrochim. Acta 29 (1973) 675.

[55] M. Trpkovska, B. Šoptrajanov, L. Pejov, Bull. Chem. Technol. Macedonia 21 (2002) 111.

[56] N. Mancilla, V. Caliva, M.C. D’Antonio, A.C. Gonzalez-Baro, E.J. Baran, J. Raman Spectrosc. 40 (2009) 915.

[57] M.C. D’Antonio, N. Mancilla, A. Wladimirsky, D. Palacios, A.C. Gonzalez-Baro, E.J. Baran, Vib. Spectrosc. 53 (2010) 218.

[58] J. Favrot, D. Vocelle, C. Sandrofy, Photochem. Photobiol. 28 (1979) 417.

[59] F.H. Allen, C.H. Bird, R.S. Rowland, P.R. Raithby, Acta Cryst. B53 (1997) 680 